\title{
AVALIAÇÃO DA ROTULAGEM E QUALIDADE FÍSICO-QUÍMICA DE GELEIAS DE UVA COMERCIALIZADAS NA CIDADE DO RIO GRANDE - RS
}

\section{EVALUATION OF LABELING AND PHYSICAL-CHEMICAL QUALITY OF GRAPE JELLY PACKAGES SOLD IN THE CITY OF RIO GRANDE -RS}

\author{
Gisele Medianeira Barbieri Moro ${ }^{1}$; Rosane da Silva Rodrigues ${ }^{2}$; Jorge Alberto Vieira Costa ${ }^{3}$, \\ Sandriane Pizato ${ }^{4}$, Wallans Raphael Couto Machado ${ }^{5}$ \\ 1,3,4,5 Universidade Federal do Rio Grande - FURG, Rio Grande - RS. E-mails: \\ Universidade Federal de Pelotas - UFPEL, Pelotas - RS. E-mail: rosane.rodrigues@ ufpel.tche.br.
}

\begin{abstract}
Resumo
O objetivo deste trabalho foi avaliar a qualidade físico-química e as informações contidas nos rótulos das embalagens de geleias de uva comercializadas na cidade do Rio Grande, RS. Geleias de uva produzidas industrialmente foram adquiridas no comércio local do Rio Grande, totalizando oito amostras, sendo seis geleias tradicionais e duas geleias light. As informações contidas nos rótulos foram avaliadas segundo a legislação brasileira vigente. As geleias foram analisadas quanto ao $\mathrm{pH}$, teor de sólidos solúveis, acidez titulável e cor. Todas as marcas de geleias estudadas apresentaram informações nutricionais no rótulo. No entanto, quanto à rotulagem geral, todas apresentaram inconformidades. Uma das amostras analisadas apresentou massa inferior ao permitido pela legislação. Quanto à análise de sólidos solúveis, 62,5\% das amostras do produto na versão tradicional apresentaram mínimo de $65^{\circ}$ Brix. A acidez titulável apresentou variação de

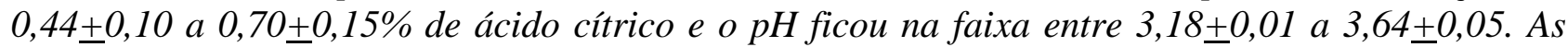
geleias light apresentaram menor luminosidade ( $\left.L^{*}\right)$. Desta forma, as geleias de uva analisadas apresentaram alguma inconformidade em relação à rotulagem geral considerando-se a legislação brasileira para este tema. No entanto, todas as marcas estudadas apresentaram informações nutricionais no rótulo. Verificou-se enquadramento do produto dentro dos limites aceitáveis para sólidos solúveis e para acidez titulável embora a maioria das amostras tenha apresentado $p H$ superior ao indicado como ideal à formação do gel. As geleias com redução calórica apresentaram menor luminosidade que as tradicionais, mas à exceção de uma, apresentou igualmente predomínio da cor vermelha.
\end{abstract}

Palavras-chave: consumidor, geleia, legislação, rótulo. 


\section{Introdução}

A viticultura ocupa um dos setores mais importantes da fruticultura brasileira, concentrada em diversas regiões, onde se destacam como maiores produtores os estados das regiões Sul, Sudeste e Nordeste, atingindo em 2010 uma produção de 1,29 milhões de toneladas de uva. Naquele ano, 43,07\% da uva produzida no País foi utilizada no processamento de vinhos, sucos e geleias, sendo o restante destinado ao mercado in natura (MELLO, 2011).

Geleias de uva se apresentam como um complemento essencial da cadeia produtiva da videira, já que frutos não classificados para comercialização in natura ou para produção vinífera, devido a fatores como cor, aroma e concentração de açúcares, podem ser aproveitados na fabricação do produto (EBERT et al., 2010). Contudo, para a elaboração de geleias de qualidade é importante que as uvas estejam maduras e com características de cor, aroma e sabor satisfatórias (ALVES, 2006).

Pela definição da legislação brasileira atual, as geleias se enquadram como produtos oriundos de frutas, inteira(s), ou em parte(s) e/ou semente(s), obtidas por secagem, e/ou laminação e/ou fermentação, e/ou concentração e/ou congelamento, e/ou outros processos tecnológicos considerados seguros para a produção de alimentos (BRASIL, 2005). Contudo, tradicionalmente considera-se geleia o produto obtido de suco de fruta que, processado, apresenta uma forma geleificada devido ao equilíbrio entre pectina, açúcares e ácidos naturalmente presentes na fruta ou adicionados (VENDRUSCOLO, MOREIRA e VENDRUSCOLO, 2009). A consistência deve ser tal que, quando extraída de seu recipiente, seja capaz de se manter no estado semissólido adequado, devendo ser acondicionada de forma a assegurar sua conservação (ALBUQUERQUE, NACCO e FARO, 1996).

A formação da geleia ocorre quando há precipitação da pectina em presença de açúcar, que atua como um agente desidratante, e na presença de íons de hidrogênio, que agem para reduzir a carga negativa sobre a pectina, formando assim uma rede de fibras não solúveis pela aglutinação desta (ALVES, 2006). Segundo Vendruscolo, Moreira e Vendruscolo (2009), as condições ótimas para formação do gel estão próximas ao pH 3,2 e teor de sólidos solúveis acima de $65 \%$.

A combinação de açúcar e ácido, tanto na qualidade como na ordem de colocação durante o processamento, deve ser respeitada para se obter uma maior qualidade da geleia (ALBUQUERQUE, NACCO e FARO, 1996). Além desses ingredientes básicos (pectina, açúcar e ácido), a incorporação de aditivos alimentares é permitida para modificar as características físicas, químicas e ou sensoriais do produto (BRASIL, 2002; 2009).

Além da garantia dos aspectos de qualidade do produto, a verificação da conformidade das informações da rotulagem é obrigatória para geleias as quais se enquadram na normativa que 
estabelece que "a rotulagem nutricional se aplica aos alimentos produzidos e comercializados, qualquer que seja sua origem, embalados na ausência do cliente e prontos para serem oferecidos ao consumidor" (BRASIL, 2003a).

Rótulo nutricional é toda inscrição destinada a informar ao consumidor sobre as propriedades nutricionais de um alimento (SINGLA, 2010). Dessa forma, os rótulos são elementos essenciais de comunicação entre produtos e consumidores, sendo necessário que as informações sejam claras e possam auxiliar na escolha adequada dos alimentos (MANTOANELLI et al., 1999).

Por determinação da legislação vigente, o rótulo deve ser fiel ao produto que o contém e ser escrito de forma legível para evitar a indução do consumidor a erros ou dúvidas, havendo, ainda, a obrigação de se mencionar no rótulo as seguintes informações: denominação de venda do alimento, lista de ingredientes, aditivos alimentares utilizados, conteúdo líquido, identificação da origem e lote, data de fabricação, prazo de validade, e instruções sobre o preparo e uso do alimento, quando necessário (BRASIL, 2002).

É por meio do rótulo que, ao adquirir um produto industrializado, o consumidor tem acesso às informações acima descritas para poder comparar marcas no momento da compra, verificar a relação entre a qualidade e o preço e, por motivos de saúde, evitar ou reduzir certos ingredientes (BRUNSO e NORGAARD, 2009).

Sendo assim, este trabalho teve por objetivo avaliar a qualidade físico-química e as informações contidas nos rótulos das embalagens de geleias de uva comercializadas na cidade do Rio Grande, RS.

\section{Material e métodos}

\section{Geleias de uva}

Geleias de uva produzidas industrialmente em várias localidades do Brasil foram adquiridas no comércio local da cidade do Rio Grande, RS. A coleta do produto foi realizada durante o mês de abril de 2011, totalizando oito amostras, sendo seis geleias tradicionais e duas geleias light, acondicionadas em embalagens de plástico e vidro com tampa rosqueável, todas dentro do prazo de validade.

\section{Análise do rótulo das embalagens}

As informações contidas nos rótulos das geleias foram avaliadas segundo a legislação brasileira vigente. Desta forma, foram adotados os critérios da Resolução RDC ANVISA n ${ }^{\circ} 259$, de 20 de setembro de 2002 (BRASIL, 2002), a qual regulamenta a Rotulagem de Alimentos Embalados; da Resolução RDC ANVISA n ${ }^{\circ}$ 360, de 23 de dezembro de 2003 (BRASIL, 2003a), que determina a Rotulagem Nutricional de Alimentos Embalados, tornando obrigatória a rotulagem nutricional; da Resolução RDC ANVISA n ³59, de 23 de dezembro de 2003 (BRASIL, 2003b), 
que estabelece as Porções de Alimentos Embalados para Fins de Rotulagem Nutricional; da Resolução RDC ANVISA n ${ }^{\circ}$ 28, de 26 de maio de 2009 (BRASIL, 2009), a qual define os aditivos alimentares com suas respectivas funções e limites máximos para geleias (de frutas, de vegetais, de mocotó e com informação nutricional complementar de baixo ou reduzido valor energético); e da Portaria INMETRO n ${ }^{\circ} 248$ de 17 de julho de 2008 (BRASIL, 2008a), a qual estabelece os critérios para a verificação do conteúdo líquido de produtos pré-medidos com conteúdo nominal igual e comercializados nas grandezas de massa e volume.

Parâmetros físico-químicos e de cor

Este trabalho foi realizado no Laboratório de Engenharia Bioquímica da Universidade Federal do Rio Grande - FURG, RS. A pesagem das amostras foi realizada em uma balança semianalítica da marca Marte, modelo A2000, com capacidade de 2000g. Primeiramente determinou-se a massa da amostra bruta, ou seja, a embalagem contendo o produto, determinando-se desta forma o peso bruto (g) da amostra. A seguir retirou-se o produto da embalagem, transferindo-o para um béquer, e determinou-se a massa da geleia (g), correspondendo ao peso líquido.

As geleias foram analisadas quanto ao $\mathrm{pH}$ a $20^{\circ} \mathrm{C}$ (potenciômetro da marca Marconi modelo PA 200), teor de sólidos solúveis (refratômetro de bancada tipo Abbé, a $20{ }^{\circ} \mathrm{C}$, expresso em ${ }^{\circ} \mathrm{Brix}$ ) e acidez titulável (método volumétrico, titulação com $\mathrm{NaOH} 0 ; 1 \mathrm{~N}$, expressa em \% de ácido cítrico). Para essas determinações foi utilizada a diluição de $5 \mathrm{~g}$ de amostra em $50 \mathrm{ml}$ de água destilada, de acordo com os procedimentos indicados pelas Normas Analíticas do Instituto Adolfo Lutz (2008). A cor das geleias foi determinada pelo sistema CIE (Comission Internatinale de E'clairage) L*a*b* (SANJINEZ-ARGANDOÑA, 2005) em equipamento colorímetro Minolta, modelo Chroma Meter CR400, através dos parâmetros de cor, sendo que o L* indica a luminosidade das amostras, indo do preto (0\%) ao branco (100\%) (CALVO e SALVADOR, 2000), coordenada de cromoticidade a*, variando do verde (-60) ao vermelho (+60), e coordenada de cromoticidade $b^{*}$, variando do azul (60) ao amarelo (+60). Esses parâmetros foram medidos diretamente nas geleias, no próprio aparelho. Todas as análises foram realizadas em triplicata.

Os dados coletados neste estudo foram apresentados por meio de gráficos e tabelas, conforme descrito por Jacques (2003), utilizando-se média e desvio-padrão.

\section{Resultados e discussão}

Análise do rótulo

Neste trabalho, verificou-se que todas as marcas de geleias estudadas apresentaram informações nutricionais no rótulo, atendendo ao previsto na Resolução RDC ANVISA n ³60/2003 (BRASIL, 2003a) e Resolução RDC ANVISA n ³59/2003 (BRASIL, 2003b).

De acordo com a RDC ANVISA n ${ }^{\circ} 360 / 2003$ (BRASIL, 2003a), é obrigatório declarar no rótulo as seguintes informações: valor energético, carboidratos, proteínas, gorduras totais, gorduras 
saturadas, gorduras trans, fibra alimentar e sódio, medida caseira da porção informada na tabela nutricional utilizando utensílios domésticos como colher, xícara, etc., bem como a informação nutricional complementar relativa à declaração facultativa de propriedades nutricionais. A legislação prevê ainda que sejam considerados isentos de gorduras trans os alimentos que contiverem valor menor ou igual a $0,2 \mathrm{~g}$ na porção declarada e que na porcentagem de valores diários (\%VD) fiquem excluídas as gorduras trans. A inclusão de gorduras trans como declaração obrigatória segue uma tendência internacional, visto que o consumo de ácidos graxos trans está associado às doenças coronarianas (GONÇALVES, 2009). As vitaminas e minerais podem ser declarados opcionalmente, desde que cada porção do alimento contenha no mínimo 5\% da ingestão diária recomendada. É permitida uma tolerância de $20 \%$ (inferior ou superior) nos valores informados no rótulo; caso seja maior, a empresa responsável deve manter a disposição os estudos que justifiquem tal variação (BRASIL, 2003a; BRASIL, 2008b).

Sendo assim, todas as amostras analisadas apresentaram o valor de referência para energia de $2000 \mathrm{Kcal}$, estando em conformidade com a legislação (BRASIL, 2003a). Quanto à porção, todas as amostras indicavam no rótulo uma porção de $20 \mathrm{~g}$, correspondendo a uma colher de sopa, atendendo ao previsto na Resolução RDC ANVISA n ³59/2003 (BRASIL, 2003b).

Segundo a legislação, a informação nutricional deve aparecer agrupada em um mesmo lugar, estruturada em forma de tabela, com os valores e as unidades em colunas. Caso o espaço seja insuficiente, pode ser utilizada a forma horizontal ou a forma linear da informação nutricional, podendo também utilizar uma declaração nutricional simplificada. Para tanto, a declaração de valor energético ou conteúdo de nutrientes deve ser substituída pela frase: "Não contém quantidade significativa de nutrientes e valor energético necessário para uma dieta diária saudável”, a qual será colocada dentro do espaço destinado para rotulagem nutricional (BRASIL, 2003a).

$\mathrm{Na}$ Tabela 1 encontram-se os resultados da descrição da rotulagem geral do produto em relação às informações de endereço do fabricante, atendimento ao consumidor, data de fabricação, prazo de validade e número de lote das geleias de uva.

Tabela 1 - Dados de identificação em rótulos de geleias de uva comercializadas na cidade do Rio Grande - RS

\begin{tabular}{lccccc}
\hline Marca & $\begin{array}{c}\text { Endereço } \\
\text { fabricante }\end{array}$ & $\begin{array}{c}\text { Atendimento ao } \\
\text { consumidor }\end{array}$ & Data fabricação & $\begin{array}{c}\text { Prazo de } \\
\text { validade }\end{array}$ & $\mathrm{N}^{\mathbf{0}}$ de lote \\
\hline $\mathrm{A}^{1}$ & $\mathrm{C}$ & $\mathrm{C}$ & $\mathrm{C}$ & $\mathrm{C}$ & $\mathrm{C}$ \\
$\mathrm{B}^{1}$ & $\mathrm{C}$ & $\mathrm{C}$ & $\mathrm{C}$ & $\mathrm{C}$ & $\mathrm{NC}$ \\
$\mathrm{C}^{1}$ & $\mathrm{C}$ & $\mathrm{C}$ & $\mathrm{C}$ & $\mathrm{C}$ & $\mathrm{NC}$ \\
$\mathrm{D}^{1}$ & $\mathrm{C}$ & $\mathrm{NC}$ & $\mathrm{C}$ & $\mathrm{C}$ & $\mathrm{C}$ \\
$\mathrm{E}^{1}$ & $\mathrm{C}$ & $\mathrm{NC}$ & $\mathrm{C}$ & $\mathrm{NC}$ \\
$\mathrm{F}^{2}$ & $\mathrm{C}$ & $\mathrm{C}$ & $\mathrm{C}$ & $\mathrm{NC}$ \\
$\mathrm{G}^{1}$ & $\mathrm{C}$ & $\mathrm{C}$ & $\mathrm{NC}$ & $\mathrm{C}$ \\
$\mathrm{H}^{2}$ & $\mathrm{C}$ & $\mathrm{C}$ & & $\mathrm{C}$ \\
\hline${ }^{1} \mathrm{Geleia} \mathrm{tradicional;}^{2} \mathrm{Geleia}$ light. & & &
\end{tabular}


Todas as geleias analisadas apresentavam o endereço do fabricante e o prazo de validade nos rótulos. A data de fabricação não constava em 25\% (n=2) das amostras. Tal informação é importante para o consumidor relativamente à verificação do prazo de validade e estimativa de armazenamento até o consumo. Em 66,7\% (n=4) das amostras analisadas constava a abreviação do mês através das três primeiras letras do mesmo. Nas demais o mês foi expresso em algarismos, não codificados, estando de acordo com a legislação (BRASIL, 2002).

Para a identificação da origem devem ser indicados no rótulo o nome (razão social) do fabricante, produtor, fracionador ou titular (proprietário) da marca, o endereço completo, o país de origem, o município e o número de registro ou código de identificação do estabelecimento fabricante junto ao órgão competente. Para essa identificação deve ser utilizada uma das expressões: "fabricado em ...", "produto ..." ou "indústria ..." (BRASIL, 2002).

Verificou-se que $25 \%(n=2)$ e $50 \%(n=4)$ das amostras não apresentaram indicação de serviço de atendimento ao consumidor e número de lote na embalagem, respectivamente. O número de lote torna possível identificar todos os dados de processo e matéria-prima utilizados para a fabricação do produto para aquele grupo, possibilitando encontrar a origem de um problema/inconformidade (TAVARES et al., 2003).

$\mathrm{Na}$ Tabela 2 estão os resultados da análise de informações como ingredientes, aditivos, instrução de armazenamento, tipo de embalagem e símbolo indicativo do tipo de embalagem das geleias de uva.

Tabela 2 - Ingredientes, aditivos, instrução de armazenamento, tipo de embalagem e símbolo indicativo do tipo de embalagem de geleias de uva comercializadas na cidade do Rio Grande - RS

\begin{tabular}{|c|c|c|c|c|c|}
\hline Marca & Ingredientes & Aditivos & $\begin{array}{c}\text { Instruções de } \\
\text { armazenamento }\end{array}$ & $\begin{array}{c}\text { Tipo de } \\
\text { embalagem }\end{array}$ & $\begin{array}{c}\text { Símbolo indicativo } \\
\text { do tipo de } \\
\text { embalagem }\end{array}$ \\
\hline $\mathrm{A}^{1}$ & $\mathrm{C}$ & $\mathrm{C}$ & $\mathrm{C}$ & Plástico & $\mathrm{NC}$ \\
\hline $\mathrm{B}^{1}$ & $\mathrm{C}$ & $\mathrm{C}$ & $\mathrm{C}$ & Plástico & $\mathrm{NC}$ \\
\hline $\mathrm{C}^{1}$ & $\mathrm{C}$ & $\mathrm{C}$ & $\mathrm{NC}$ & Plástico & $\mathrm{NC}$ \\
\hline $\mathrm{D}^{1}$ & $\mathrm{C}$ & $\mathrm{C}$ & $\mathrm{C}^{\mathrm{i}}$ & Plástico & $\mathrm{NC}$ \\
\hline $\mathrm{E}^{1}$ & $\mathrm{C}$ & $\mathrm{C}$ & $\mathrm{C}$ & Plástico & $\mathrm{NC}$ \\
\hline $\mathrm{F}^{2}$ & $\mathrm{C}$ & $\mathrm{C}$ & $\mathrm{C}$ & Plástico & $\mathrm{NC}$ \\
\hline $\mathrm{G}^{1}$ & $\mathrm{C}$ & $\mathrm{C}$ & $\mathrm{C}$ & Plástico & $\mathrm{NC}$ \\
\hline $\mathrm{H}^{2}$ & $\mathrm{C}$ & $\mathrm{C}$ & $\mathrm{C}$ & Vidro & $\mathrm{NC}$ \\
\hline
\end{tabular}

$\mathrm{C}=$ Consta no rótulo; $\mathrm{C}^{\mathrm{i}}=$ Consta Ilegível no rótulo; $\mathrm{NC}=$ Não Consta no rótulo.

Todas as amostras pesquisadas indicaram ingredientes no rótulo cuja lista foi precedida da expressão “ingredientes:”.

Com exceção de alimentos com um único ingrediente deve sempre constar no rótulo uma lista de ingredientes, essa lista deve constar no rótulo precedida da expressão "ingredientes:" ou "ingr.:", e devem constar em ordem decrescente da respectiva proporção (BRASIL, 2002). Os aditivos alimentares devem ser declarados fazendo parte da lista de ingredientes, sendo que nesta 
declaração deve constar a função principal ou fundamental do aditivo no alimento e seu nome completo ou seu número INS (Sistema Internacional de Numeração, Codex Alimentarius FAO/OMS), ou ambos. Quando houver mais de um aditivo alimentar com a mesma função, pode ser mencionado um em continuação ao outro, agrupando-os por função. Os aditivos alimentares devem ser declarados depois dos ingredientes (BRASIL, 2002) o que foi observado nos rótulos das geleias, no entanto, em nenhuma delas estava explícita a função do aditivo acrescentado, concordando com o estudo realizado por Tavares et al. (2003).

Quanto às instruções de armazenamento, informações necessárias para que o produto alimentício tenha as mesmas características no término do prazo de validade, constatou-se que a amostra C não apresentou este dado. Além disso, dentre as que apresentaram esta informação no rótulo, uma estava de forma ilegível.

De acordo com a legislação, nos rótulos das embalagens de alimentos que exijam condições especiais para sua conservação deve ser incluída uma legenda com caracteres bem legíveis, indicando as precauções necessárias para manter suas características normais, devendo ser indicadas as temperaturas máximas e mínimas para a conservação do alimento e o tempo que o fabricante, produtor ou fracionador garante sua durabilidade nessas condições (BRASIL, 2002). Com relação à legibilidade das informações contidas nos rótulos, $25 \%(\mathrm{n}=2)$ das amostras analisadas estavam em desacordo com a legislação (BRASIL, 2002), uma vez que a distribuição das informações obrigatórias não estava adequada.

Outra informação estudada no rótulo dos produtos pesquisados neste trabalho foi a presença do símbolo indicativo do tipo da embalagem. Esta informação pode auxiliar o consumidor na seleção dos materiais para reciclagem (TAVARES et al., 2003). No entanto, nesta pesquisa, nenhuma das amostras apresentou essa informação, o que também foi observado por Tavares et al. (2003).

A discriminação no rótulo dos componentes utilizados para a fabricação de produtos alimentícios é mencionada na Resolução RDC ANVISA nº. 259/2002 (BRASIL, 2002). Desta forma, na Tabela 3 está uma relação dos componentes citados como parte dos ingredientes dos produtos pesquisados.

Todas as geleias indicaram a presença de açúcar e pectina na formulação e 62,5\% $(n=5)$ indicavam também a presença de xarope de glicose.

Quanto à discriminação no rótulo da presença de uva na composição do produto, constatouse que todas as amostras indicavam a presença da fruta e em nenhuma foi indicada a adição de água. 
Tabela 3 - Lista de ingredientes e aditivos citados nos rótulos de geleias de uva comercializadas na cidade do Rio Grande - RS

\begin{tabular}{|c|c|c|c|c|c|c|c|}
\hline \multirow[b]{2}{*}{ Marca } & \multicolumn{5}{|c|}{ Ingredientes } & \multicolumn{2}{|c|}{ Aditivos } \\
\hline & Açúcar & $\begin{array}{l}\text { Xarope } \\
\text { glicose }\end{array}$ & Uva & Pectina & Água & Conservante & Acidulante \\
\hline $\mathrm{A}^{1}$ & $\mathrm{C}$ & $\mathrm{NC}$ & $\mathrm{C}$ & $\mathrm{C}$ & $\mathrm{NC}$ & BS & $\mathrm{NC}$ \\
\hline $\mathrm{B}^{1}$ & $\mathrm{C}$ & $\mathrm{C}$ & $\mathrm{C}$ & $\mathrm{C}$ & $\mathrm{NC}$ & SP & $\mathrm{AC}$ \\
\hline $\mathrm{C}^{1}$ & $\mathrm{C}$ & $\mathrm{C}$ & $\mathrm{C}$ & $\mathrm{C}$ & $\mathrm{NC}$ & SP & $\mathrm{AC}$ \\
\hline $\mathrm{D}^{1}$ & $\mathrm{C}$ & $\mathrm{NC}$ & $\mathrm{C}$ & $\mathrm{C}$ & $\mathrm{NC}$ & SP & $\mathrm{AL}$ \\
\hline$E^{1}$ & $\mathrm{C}$ & $\mathrm{C}$ & $\mathrm{C}$ & $\mathrm{C}$ & $\mathrm{NC}$ & SP & $\mathrm{NC}$ \\
\hline $\mathrm{F}^{2}$ & $\mathrm{C}$ & $\mathrm{C}$ & $\mathrm{C}$ & $\mathrm{C}$ & $\mathrm{NC}$ & SP & $\mathrm{NC}$ \\
\hline $\mathrm{G}^{1}$ & $\mathrm{C}$ & $\mathrm{C}$ & $\mathrm{C}$ & $\mathrm{C}$ & $\mathrm{NC}$ & DE/BS & $\mathrm{AL}$ \\
\hline $\mathrm{H}^{2}$ & $\mathrm{C}$ & $\mathrm{NC}$ & $\mathrm{C}$ & $\mathrm{C}$ & $\mathrm{NC}$ & SP & $\mathrm{AC}$ \\
\hline
\end{tabular}

A água deve ser declarada na lista de ingredientes, exceto quando faça parte de salmoura, xaropes, molhos, caldos ou outros similares, e estes ingredientes compostos sejam declarados como tais na lista de ingredientes. Não é necessário a declaração de água e outros componentes voláteis que se evaporem durante a fabricação (BRASIL, 1998).

Ressalta-se ainda que uma das amostras indicava no rótulo a presença de corante artificial vermelho Bordeaux, estando em desacordo com a RDC ANVISA nº 28 , de 26 de maio de 2009 (BRASIL, 2009) na qual não consta este corante na lista dos permitidos para este tipo de produto.

Neste trabalho se determinou a massa do produto em cada embalagem com a finalidade de verificar se a quantidade nominal indicada no rótulo condizia com a aferida em laboratório. Estes dados, além da especificação das geleias de uva estudadas, são apresentados na Tabela 4.

Tabela 4 - Massa declarada, média ( $n=3$ ) e desvio padrão, da massa aferida de geleias de uva comercializadas na cidade do Rio Grande - RS

\begin{tabular}{|c|c|c|}
\hline Marca & Massa declarada (g) & Massa aferida (g) \\
\hline$\overline{A^{1}}$ & 450 & $443,95 \pm 0,01$ \\
\hline $\mathrm{B}^{1}$ & 400 & $399,79 \pm 0,01$ \\
\hline $\mathrm{C}^{1}$ & 400 & $398,72 \pm 0,01$ \\
\hline $\mathrm{D}^{1}$ & 400 & $396,46 \pm 0,01$ \\
\hline$E^{1}$ & 400 & $392,71 \pm 0,01$ \\
\hline $\mathrm{F}^{2}$ & 250 & $252,37 \pm 0,05$ \\
\hline $\mathrm{G}^{1}$ & 400 & $395,12 \pm 0,01$ \\
\hline $\mathrm{H}^{2}$ & 200 & $187,11 \pm 0,01$ \\
\hline
\end{tabular}

Conforme observado na Tabela 4, a maioria das amostras analisadas apresentou massa, expressa em gramas, inferior a indicada no rótulo. Somente uma $(12,5 \%)$ das amostras apresentou quantidade superior ao descrito no rótulo. Pode-se inferir que tenha havido alguma deficiência quanto aos procedimentos de aferição dos equipamentos de enchimento das embalagens, sugerindo 
desta forma uma maior atenção por parte do fabricante. No entanto, para o peso líquido do produto são observados os critérios de tolerância constantes na Portaria do INMETRO n ${ }^{\circ}$. 248/2008, a qual tolera uma variação de até 5\% para mais ou para menos no peso líquido do produto (BRASIL, 2008a). Desta forma, a geleia $\mathrm{H}$ apresentou variação maior que 5\% para o peso líquido do produto, estando em inconformidade com a Portaria supracitada.

Quanto ao peso líquido, as unidades legais de quantidade nominal quando escritas por extenso ou representadas com símbolos de uso obrigatório devem ser precedidos das expressões: "Conteúdo Líquido", "Cont. Líquido", "Peso Líquido" (BRASIL, 2002).

\section{Parâmetros físico-químicos e de cor}

Não existem padrões de qualidade específicos a serem seguidos no caso da produção de geleias. Mesmo assim, alguns parâmetros físico-químicos são importantes para avaliação da qualidade do produto.

Os dados referentes às avaliações físico-químicas nas geleias de uva são apresentados na Tabela 5.

Tabela 5 - Valores médios ( $\mathrm{n}=3$ ) e desvio padrão de sólidos solúveis, acidez titulável e pH de geleias de uva

\begin{tabular}{cccc}
\multicolumn{4}{c}{ comercializadas na cidade do Rio Grande $-\mathrm{RS}$} \\
\hline \\
\cline { 2 - 3 } & $\begin{array}{c}\text { Sólidos solúveis } \\
\left({ }^{\circ} \text { Brix }\right)\end{array}$ & $\begin{array}{c}\text { Acidez titulável } \\
(\% \text { ácido cítrico) }\end{array}$ & $\mathrm{pH}$ \\
\hline $\mathrm{A}^{1}$ & $68,0 \pm 0,42$ & $0,46 \pm 0,11$ & $3,64 \pm 0,05$ \\
$\mathrm{~B}^{1}$ & $70,0 \pm 0,58$ & $0,62 \pm 0,05$ & $3,36 \pm 0,05$ \\
$\mathrm{C}^{1}$ & $72,3 \pm 0,58$ & $0,63 \pm 0,40$ & $3,41 \pm 0,01$ \\
$\mathrm{D}^{1}$ & $66,0 \pm 0,36$ & $0,51 \pm 0,15$ & $3,23 \pm 0,01$ \\
$\mathrm{E}^{1}$ & $71,0 \pm 0,11$ & $0,59 \pm 0,06$ & $3,44 \pm 0,05$ \\
$\mathrm{~F}^{2}$ & $60,0 \pm 0,38$ & $0,55 \pm 0,11$ & $3,58 \pm 0,01$ \\
$\mathrm{G}^{1}$ & $60,0 \pm 0,05$ & $0,70 \pm 0,15$ & $3,18 \pm 0,01$ \\
$\mathrm{H}^{2}$ & $32,0 \pm 0,17$ & $0,44 \pm 0,10$ & $3,54 \pm 0,05$ \\
\hline
\end{tabular}

Observa-se que 5 das 6 amostras de geleias tradicionais apresentaram valores acima de 65² Brix para sólidos solúveis, o que também foi observado por Alves (2006) com geleias comercializadas na cidade de Santa Maria, RS. Este valor mínimo era estabelecido na Resolução Normativa CSN nº. 12/1978 (BRASIL, 1978) que, embora revogada pela Resolução ANVISA RDC $\mathrm{n}^{\mathrm{o}} .272 / 2005$ (BRASIL, 2005a), ainda pode ser tecnicamente considerado em função das características físicas, químicas e de estabilidade do produto. Desta forma, concentração de sólidos solúveis em torno de $64^{\circ}$ Brix origina geleias moles, 67-68 ${ }^{\circ}$ Brix resultam em geleias ótimas e acima de $71^{\circ}$ Brix em geleias duras (VENDRUSCULO, MOREIRA e VENDRUSCULO, 2009).

Para fins de avaliação, a análise da concentração de açúcar nas geleias comerciais light segue a Portaria n ${ }^{\circ}$ 27/1998, que regulamenta a informação nutricional complementar, normatizando 
a produção e comercialização de produtos light. De acordo com esta Portaria, deve haver uma redução mínima de 25\% no total de calorias encontradas nesses produtos (BRASIL, 1998).

De acordo com Siguemoto (1993), os sólidos solúveis estão relacionados diretamente com a formação do gel uma vez que se ligam às moléculas de água, favorecendo a estrutura da rede tridimensional. Além disso, o açúcar age como um conservante inibindo o crescimento de microorganismos, pelo fato de aumentar a pressão osmótica com a consequente redução da atividade de água (ALMEIDA, SCHMIDT e GASPARINO FILHO, 1999), melhorando a aparência, sabor e rendimento da geleia (FOPPA, TSUZUKI e SANTOS, 2009). Portanto, a padronização de sólidos solúveis totais na fabricação de geleias é de importância fundamental no controle de qualidade das mesmas.

No que se refere à acidez titulável, conforme Jackix (1988), as geleias de um modo geral devem conter de 0,3 a $0,8 \%$ de acidez, pois em valores acima de $1 \%$ ocorre a exsudação do líquido (sinerese), enquanto que em baixa acidez, com valores menores que $0,3 \%$, a rede de gel torna-se fraca. Neste estudo, verificou-se que as amostras analisadas apresentaram variações de acidez titulável de 0,44+0,10 a 0,70 $\underline{+0,15 \%}$ de ácido cítrico, estando em conformidade com as orientações mencionadas pela mesma autora.

Segundo Morais (2000), uma boa geleificação ocorre na faixa de valores de $\mathrm{pH}$ entre 3,0 e 3,2 enquanto que para Jackix (1988) o valor do pH deve estar situado entre 3,0 e 3,4, sendo que abaixo de 3,0 ocorre tendência à sinerese. Neste trabalho, verificou-se que o pH ficou na faixa entre 3,18 $\pm 0,01$ e 3,64 $\pm 0,05$, semelhante ao observado por Alves (2006). Do total de geleias analisadas, $62,5 \%(\mathrm{n}=5)$ apresentaram pH superior a 3,4. A baixa acidez da geleia impede a formação do gel, tornando-a fraca (JACKIX, 1988).

Para uma melhor caracterização da geleia de uva, realizou-se análise de cor através do Sistema CIE L*a*b* cujos dados são apresentados na Tabela 6.

Tabela 6 - Valores médios ( $\mathrm{n}=3$ ) e desvio padrão de $\mathrm{L}^{*}$ (luminosidade), cromoticidade $\mathrm{a}^{*}$ e cromoticidade $\mathrm{b}^{*}$ de geleias de uva comercializadas na cidade do Rio Grande, RS

\begin{tabular}{|c|c|c|c|}
\hline Marca & L* (luminosidade) & Cromoticidade $\mathrm{a}^{*}$ & Cromoticidade $\mathrm{b}^{*}$ \\
\hline$A^{1}$ & $25,34 \pm 0,08$ & $2,90 \pm 0,10$ & $2,60 \pm 0,10$ \\
\hline $\mathrm{B}^{1}$ & $23,60 \pm 0,04$ & $3,25 \pm 0,05$ & $2,10 \pm 0,05$ \\
\hline $\mathrm{C}^{1}$ & $25,70 \pm 0,05$ & $3,10 \pm 0,06$ & $1,50 \pm 0,05$ \\
\hline $\mathrm{D}^{1}$ & $23,50 \pm 0,05$ & $2,70 \pm 0,05$ & $2,15 \pm 0,05$ \\
\hline $\mathrm{E}^{1}$ & $25,10 \pm 0,05$ & $2,56 \pm 0,05$ & $1,90 \pm 0,05$ \\
\hline $\mathrm{F}^{2}$ & $22,90 \pm 0,06$ & $7,90 \pm 0,06$ & $7,70 \pm 0,05$ \\
\hline $\mathrm{G}^{1}$ & $24,40 \pm 0,06$ & $3,75 \pm 0,10$ & $1,45 \pm 0,07$ \\
\hline $\mathrm{H}^{2}$ & $20,10 \pm 0,06$ & $10,20 \pm 0,10$ & $1,42 \pm 0,07$ \\
\hline
\end{tabular}


$\mathrm{Na}$ indústria de geleias a cor é um parâmetro importante, pois será a primeira impressão dada ao consumidor e também pode ser relacionada à estabilidade durante o armazenamento (ARAUJO, 2005).

A cor violeta da uva no estágio maduro é devido à presença de antocianinas, as quais são responsáveis pelos pigmentos que variam do vermelho vivo ao violeta e azul. Quimicamente, esses pigmentos são compostos fenólicos pertencentes ao grupo dos flavonóides e cuja coloração é bastante influenciada pelo $\mathrm{pH}$, temperatura, entre outros fatores (BOBBIO e BOBBIO, 2003; DAMODARAN, PARKIN e FENNEMA, 2010).

A luminosidade indica o quão clara ou escura é a geleia. Observa-se que a amostra $\mathrm{H}$ apresentou menor luminosidade seguida da amostra F comparativamente às demais, provavelmente devido à quantidade de antocianinas presente na geleia. Dessa forma, quanto maior a quantidade de antocianinas, mais escura ela é, apresentando maior luminosidade, possivelmente devido à menor degradação deste pigmento. Isso pode ser explicado pelo fato das antocianinas serem facilmente degradadas pelo calor. Sendo assim, para atingir a quantidade de sólidos solúveis na geleia tradicional precisa-se de mais calor do que para a geleia light, consequentemente a perda de antocianinas é maior na geleia tradicional (ARAUJO, 2005). A luminosidade também está associada à quantidade de sólidos solúveis presentes no produto. Produtos com teor reduzido de sólidos solúveis, como geleias light, apresentam tendência à perda de coloração, consequentemente apresentam menor luminosidade (VENDRAMEL, CÂNDIDO e CAMPOS, 1997).

Quanto à cromaticidade $\mathrm{a}^{*}$, a amostra $\mathrm{H}$ apresentou valor superior ao restante. Entretanto, o valor referente à cromaticidade $b^{*}$ apresentou valor mais elevado na amostra $\mathrm{F}$. Estes resultados evidenciam que a amostra $\mathrm{H}$ apresentou maior tendência à cor vermelha, e a amostra $\mathrm{F}$ maior tendência ao amarelo.

No estudo de Alves (2006) as geleias tradicionais apresentaram maior luminosidade quando comparada às geleias de baixa caloria. Esse mesmo estudo demonstrou que a cromaticidade $\mathrm{a}^{*}$ foi superior em geleias diet, porém, nesse mesmo tipo de geleia a cromoticidade $b^{*}$ foi menor, concordando com essa pesquisa.

Sendo assim, pequenas degradações do pigmento resultam em maior impacto visual do que em geleias tradicionais, as quais apresentam alta concentração de antocianinas e sólidos solúveis.

\section{Conclusões}

As geleias de uva comercializadas na cidade do Rio Grande - RS apresentaram alguma inconformidade em relação à rotulagem geral considerando-se a legislação brasileira para este tema. No entanto, todas as marcas estudadas apresentaram informações nutricionais no rótulo. Verificouse enquadramento do produto dentro dos limites aceitáveis para sólidos solúveis e para acidez 
titulável embora a maioria das amostras tenha apresentado $\mathrm{pH}$ superior ao indicado como ideal à formação do gel. As geleias com redução calórica apresentaram menor luminosidade que as tradicionais, mas, à exceção de uma, apresentou igualmente predomínio da cor vermelha.

\begin{abstract}
The objective of this study was to evaluate the physical-chemical quality and information on the labels of packages of grape jelly sold in the city of Rio Grande - RS. Industrially produced grape jelly were acquired in the local Rio Grande, a total of eight samples, six traditional jams and jellies two light. The information on the labels was evaluated according to Brazilian legislation. The jams were analyzed for $\mathrm{pH}$, soluble solids, acidity and color. All brands of jams had studied nutrition information on the label. However, all showed non-compliance on the labeling rule. One of the samples analyzed showed mass lower than allowed by law. The analysis of soluble solids, $62.5 \%$ of the samples in the traditional version of the product had a minimum of $65^{\circ}$ Brix. The acidity changed by $0.44 \pm 0.10$ to $0.70 \pm 0.15 \%$ citric acid and the $\mathrm{pH}$ was in the range of $3.18 \pm 0.01$ to $3.64 \pm 0.05$. Jellies light had lower lightness $\left(L^{*}\right)$. Thus, the grape jelly analyzed showed some disagreement regarding the general labeling considering the Brazilian legislation for this issue. However, all the brands studied had nutritional information on the label. It is the product framework within acceptable limits for soluble solids and acidity although most samples have shown a pH greater than indicated as the ideal to gel formation. Jellies with calorie reduction were less than traditional light but, except for one, also presented a predominance of red.
\end{abstract}

Key-words: consumer, jam, legislation, label.

\title{
Referências
}

ALBUQUERQUE, J. P.; NACCO, R.; FARO, A. Avaliação global de geleias de uva através do método de dados difusos. Ciência e Tecnologia de Alimentos, v . 16, n. 3, p. 250-254, 1996.

ALMEIDA, M. E. M.; SCHMIDT, F. L.; GASPARINO FILHO, J. Processamento de compotas, doces em massa e geleias: fundamentos básicos. Campinas: ITAL/FRUTHOTEC, 1999.

ALVES, A. O. Presença de trans-resveratrol em geleias de uva e sua relação com a radiação UV. 2006. $143 p$. Dissertação (Mestrado em Ciência e Tecnologia de Alimentos) - Programa de Pós-Graduação em Ciência e Tecnologia de Alimentos. Santa Maria: Universidade Federal de Santa Maria.

ARAUJO, P. G. L. Conservação pós-colheita e estabilidade de polpa congelada de acerolas Apodi, Cereja, Frutacor, II 47/1, Roxinha e Sertaneja. 2005. 79p. Dissertação (Mestrado em Tecnologia de Alimentos) - Programa de Pós-Graduação em Tecnologia de Alimentos. Fortaleza: Universidade Federal do Ceará.

BOBBIO, F. O.; BOBBIO, P. Introdução à química de alimentos. 3.ed. São Paulo: Varela, 2003.

BRASIL. Ministério da Saúde. Agência Nacional da Vigilância Sanitária. Resolução CNNPA n ${ }^{\circ} 12$, de 24 de julho de 1978. Normas Técnicas Especiais do Estado de São Paulo, relativas a alimentos e bebidas. Diário Oficial da União, Brasília, DF, 24 jul. 1978.

BRASIL. Ministério da Saúde. Agência Nacional da Vigilância Sanitária. Portaria n ²7, de 13 de janeiro de 1998. Regulamento Técnico referente à Informação Nutricional Complementar (declarações relacionadas ao conteúdo de nutrientes). Diário Oficial da União, Brasília, DF, 16 jan. 1998.

BRASIL. Ministério da Saúde. Agência Nacional da Vigilância Sanitária. Resolução RDC n ²59, de 20 de setembro de 2002. Regulamento Técnico para Rotulagem de Alimentos Embalados. Diário Oficial da União, Brasília, DF, 23 set. 2002. 
BRASIL. Ministério da Saúde. Agência Nacional da Vigilância Sanitária. Resolução RDC n º360, de 23 de dezembro de 2003. Regulamento Técnico de Rotulagem Nutricional de Alimentos Embalados, tornando obrigatória a rotulagem nutricional. Diário Oficial da União, Brasília, DF, 26 dez. $2003 a$.

BRASIL. Ministério da Saúde. Agência Nacional da Vigilância Sanitária. Resolução RDC n ${ }^{\circ} 359$, de 23 de dezembro de 2003. Regulamento Técnico de Porções de Alimentos Embalados para Fins de Rotulagem Nutricional. Diário Oficial da União, Brasília, DF, 26 dez. 2003b.

BRASIL. Ministério da Saúde. Agência Nacional da Vigilância Sanitária. Resolução RDC n º272, de 22 de setembro de 2005. Regulamento Técnico para Produtos de Vegetais, Produtos de Frutas e Cogumelos Comestíveis. Diário Oficial da União, Brasília, DF, 23 set. 2005.

BRASIL. Ministério da Indústria, do Comércio e do Turismo. Instituto Nacional de Metrologia, Normalização e Qualidade Industrial. Portaria n ${ }^{\circ} 248$ de 17 de julho de 2008. Regulamento Técnico Metrológico que estabelece os critérios para a verificação do conteúdo líquido de produtos pré-medidos com conteúdo nominal igual e comercializados nas grandezas de massa e volume. Diário Oficial da União, Brasília, DF, 22 jul. 2008 a.

BRASIL. Ministério da Saúde. Agência Nacional da Vigilância Sanitária. Rotulagem Nutricional Obrigatória: manual de orientação aos consumidores educação para o consumo saudável. Brasília: ANVISA/Universidade de Brasília, 2008b.

BRASIL. Ministério da Saúde. Agência Nacional da Vigilância Sanitária. Resolução RDC n ${ }^{\circ} 28$, de 26 de maio de 2009. Atribuição de aditivos alimentares, suas funções e seus limites máximos para geleias (de frutas, de vegetais, de mocotó e com informação nutricional complementar de baixo ou reduzido valor energético). Diário Oficial da União, Brasília, DF, 27 mai. 2009.

BRUNSO, K.; NORGAARD, M. K. Families' use of nutritional information on food labels. Food Quality and Preference, v. 20, n. 8, p. 597-606, 2009. http://dx.doi.org/10.1016/j.foodqual.2009.07.005

CALVO, C.; SALVADOR, A. Use of natural colorants in food gels. Influence of Composition of gels on their colour and study of their stability during storage. Food Hydrocolloids, Spain, v. 14, n. 5, p. 439 443, 2000.

DAMODARAN, S.; PARKIN, K.; FENNEMA, O. Química de alimentos de Fennema. 4. ed. Porto Alegre: Artmed, 2010.

EBERT, L. C.; SILVA, H. R.; ORSOLINI, A.; PALEZI, S. C.; GIULIANI, F.; DEMORI, A. B.; RICHARDS, N. S. P. S. Geleia de uva com reduzido teor calórico: formulação e caracterização físico-química e sensorial. In: SEMINÁRIO INTERINSTITUCIONAL DE ENSINO, PESQUISA E EXTENSÃO (XIII MOSTRA DE INICIAÇÃO CIENTIFICA E VIII MOSTRA DE EXTENSÃO, 15, 2010, Cruz Alta). Anais... Cruz Alta: Universidade de Cruz Alta, 2010.

FOPPA, T.; TSUZUKI, M. M.; SANTOS, C. E. S. Caracterização físico-química da geleia de pêra elaborada através de duas cultivares diferentes: pêra D’água (Pyrus communis L.) e Housui (Pyrus pyrifolia Nakai). Revista Brasileira de Produtos Agroindustriais, Campina Grande, v. 11, n. 1, p. 21-25, 2009.

GONÇALVES, É. C. B. A. Análise de alimentos: uma visão química da nutrição. 2. ed. São Paulo: Varela, 2009.

INSTITUTO ADOLFO LUTZ. Métodos físico-químicos para análise de alimentos. São Paulo: Instituto Adolfo Lutz, 2008. (Versão online)

JACKIX, M. H. Geleias e doces em massa. In: Doces, geleias e frutas em calda. 2. ed. São Paulo: Unicamp, 1988. p.85-158.

JACQUES, S. C. Bioestatística: princípios e aplicações. Porto Alegre: Artmed, 2003.

MANTOANElli, G.; COlUCCI, A. C. A.; PHILIPPI, S. T.; FISBERG, R.; LATTERZA, A. R.; CRUZ, A. T. R. Avaliação de rótulos e embalagens de alimentos infantis: bebida láctea, iogurte e queijo tipo "petit suisse". Higiene Alimentar, Itapetininga, v. 13, n. 60, p. 21-8, 1999.

MELLO, L. M. R. Vitinicultura brasileira: panorama 2010. Embrapa Uva e Vinho, 2011, disponível em: <http:// <www.cnpuv.embrapa.br/publica/artigos/prodvit2010.pdf>. Acesso em: 26 de junho de 2011. 
MORAIS, J. Como montar e operar uma pequena fábrica de doces e geleias. Viçosa: Centro de Produções Técnicas, 2000 .

SANJINÉZ-ARGANDOÑA, E. J. Goiabas desidratadas osmoticamente e secas: avaliação de um sistema osmótico semi-contínuo, da secagem e da qualidade. 2005. 172p. Tese (Doutorado em Engenharia de Alimentos). Campinas: Universidade Estadual de Campinas.

SINGLA, M. Usage and understanding of food and nutritional labels among Indian consumers. Journal British Food, v. 112, n. 1, p. 83-92, 2010. http://dx.doi.org/10.1108/00070701011011227

TAVARES, L. B. B.; MACHADO, R.; BLEMER, R.; CARNEIRO, A. Avaliação das informações contidas nos rótulos das embalagens de geleias e doces sabores morango e tutti-fruti. Alimentos e Nutrição, v. 14, n. 1, p. 27-33, 2003.

VENDRAMEL, S. M. R.; CÂNDIDO, L. M. B.; CAMPOS, A. M. Avaliação reológica e sensorial de geleias com baixo teor de sólidos solúveis com diferentes hidrocolóides obtidas a partir de formulações em pó. Boletim do Centro de Pesquisa de Processamento de Alimentos, v. 15, n. 1, p. 37-56, 1997.

VENDRUSCULO, C. T.; MOREIRA, A. S.; VENDRUSCULO, J. L. S. Geleias, doces cremosos e em massa. Pelotas: Universidade Federal de Pelotas, 2009.

Submetido em 20 set. 2011, Aceito para publicação em 21 dez. 2012. 